\title{
Evaluation of Multi-Model Hindcasts of Overland Precipitation for Georgia
}

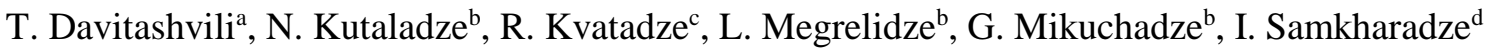 \\ a Ilia Vekua Institute of Applied Mathematics of Ivane Javakhishvili Tbilisi State University, 2 \\ University Street, 0186, Tbilisi, Georgia \\ ${ }^{\mathrm{b}}$ National Environmental Agency of Ministry of Environment Protection and Agriculture of Georgia, \\ 150, David Agmashenebeli Ave., 0112, Tbilisi, Georgia \\ ${ }^{\mathrm{c}}$ Georgian Research and Educational Networking Association GRENA, 4a, Chovelidze Street, 0108, \\ Tbilisi, Georgia \\ dvane Javakhishvili Tbilisi State University, 1, Chavchavadze Ave., 0179, Tbilisi, Georgia
}

Received: May 25, 2021. Revised: June 30, 2021. Accepted: July 5, 2021. Published: July 14, 2021.

\begin{abstract}
- this study evaluates the ability of several Regional Climate Models (RCMs) to simulate rainfall patterns in the South Caucasus region. In total, $8 \mathrm{RCM}$ simulations were assessed against the CRU observational database over different domains, among them two from the Coordinated Regional Climate Downscaling Experiment (CORDEX). Seasonal climatology, annual rainfall cycles and interannual variability in RCM outputs were estimated for 8 homogeneous sub-regions against several observational datasets. Different metrics covering from monthly and seasonal to annual time scales are analyzed over the region of interest. The results confirm the distinct capabilities of climate models in capturing the local features of the climatic conditions of the South Caucasus region. At the same time, the analysis shows significant deviations in individual models depending on the sub-region and season; however, the ensemble mean is in better agreement with observations than individual models. Overall, the analysis presented here demonstrates that, the multi-model ensemble mean adequately simulates rainfall in the South Caucasus and, therefore, it can be used to assess future climate predictions for the region. This work promotes the selection of RCM runs with reasonable performance in the South Caucasus region, from which, for the first time, a high-resolution biasadjusted climate database can be generated for future risk assessment and impact studies.
\end{abstract}

Keywords - Gridded data, hindcast, reanalysis, regional climate models (RCMs)

\section{INTRODUCTION}

Assessing the anticipated climate variations and change on region scale is highly important. The primary tool for projecting climate are global climate models (GCMs), output of which requires to be downscaled on a finer scale for impact study, for which regional climate models (RCM) are used. Modeling of climate predictions contains many uncertainties, arising from several sources, such as incomplete model formulations, future emission scenarios, and many other factors. Model errors are probably the most viable to characterize, and potentially remedy to reduce the uncertainty. Thus, Climate models evaluation is necessary step for model development and improvements for assessing and correcting model biases [1-3].

Design and distribution of global climate model simulations of the past, current, and future climate by Coupled Model Inter-comparison Project (CMIP) is coordinated and has long history of evaluation of the fidelity in simulating the presentday climate of multiple GCMs as a fundamental step in estimating the uncertainty in future climate projections. Systematic multi-model RCM experimentations and observation-based evaluations are much less mature than those for GCM studies. GCMs operate all over the world, and this makes their comparison or evaluation more accessible. RCMs are focused on a specific geographical area, thus all regions are not equally explored and evaluated [4-8].

The CORDEX program was established as the first activity of the Task Force on Regional Climate Downscaling established by World Climate Research Program (WCRP). Common experimental designs in CORDEX are advantageous 
INTERNATIONAL JOURNAL OF ENERGY and ENVIRONMENT DOI: $10.46300 / 91012.2021 .15 .10$

for many practical purposes including model evaluations, uncertainty assessments, and constructing multi-model ensemble (ENS) [9-11]. The Coordinated Regional Climate Downscaling Experiment (CORDEX) initiative has made a huge number of regional climate predictions available in various domains worldwide. This information is critical for the design of adaptation strategies and policymaking. The challenge is to assess potential multi-domain inconsistency while overlapping regions and to develop appropriate ensemble methods that try to make the most of all available information [12-13].

There are a big number of simulations in Europe, Mediterranean, Africa and North America (CORDEX domains), with numerous RCMs, different resolutions and experiments. Number of leading scientific institutes and communities are involved in effort to develop regional climate and earth system science in the mentioned regions [14-15]. Within the framework of these activities the effectiveness of separate RCMs has been studied. Uncertainties in regional climate simulation, within the multi models, multi-domains and resolution system were estimated [16-17]. Also, uncertainties in the so-called reference data, i.e. in gridded observations or analyses data were investigated. The evaluation criteria and suitable metrics for ensembles have been determined. The value of the EURO-CORDEX ensemble is shown via number of peer-reviewed studies and its use in the development of climate services. Evaluations of the EUR-44 and EUR-11 ensembles also show the benefits of higher resolution. Added value of regional downscaling with respect to scale, uncertainty, processes, and phenomena was investigated in several papers. However, significant challenges remain. Further development of scientific understanding aims to explore issues such as local-regional phenomena at convection-permitting scales and the impacts of land cover changes on regional climate across spatial and temporal scales. For solution these tasks flagship pilot study (FPS) were initiated [18-19].

This work focus on hindcast evaluation of precipitation pattern over South Caucasus region, which is highly variable both in space and in time. The territory unfortunately not fully covered with EURO and MED CORDEX domains, were lots of RCM simulations are available and rainfall across the both domains is well investigated. Only CAS (Central Asia) and MENA (Middle East and North Africa) - CORDEX domains overlaps our target area. Several simulations became available for resent years in these domains, also some study results are presented in scientific papers focusing on different geographical areas inside of the domain [20-22]. However even the main climate parameters - temperature and precipitation is not evaluated for South Caucasus region. This first demonstration case study focus on hindcast evaluation in the multi-model, multi-domain ensemble of an annual rainfall cycles, seasonal climatology, and interannual variability [2324].

This study evaluates the 6 RCM simulations over the
T. Davitashvili, N. Kutaladze, R. Kvatadze, L. Megrelidze, G. Mikuchadze, I. Samkharadze

Georgia using Regional Climate Model Evaluation System (RCMES). We include in this research 2 RCMs' (RegCM v 4.7.0 and WRF-ARW v3.9.1.1) simulations over the domain centered to Georgia performed by us and 6 simulations over MENA and CAS domains. Such a choice has resulted in the fact that the evolutionary simulations are available only for these models on ESGF (Earth System Grid Federation)CORDEX archive.

Section I provides details of the experimental design including the evaluation domain, RCMs, reference datasets; section II - reference data and models used in the study; section III provides details of the Regional Climate Model Evaluation System (RCMES) used in the model evaluation; Section IV - climate description of country; Section V presents the evaluation of RCM skill in simulating the targeted variables and examines the uncertainties in model evaluation related with reference data; results are summarized in the section VI.

\section{DATA}

In our study we have used several data archives, most of them are available from the federative ESGF infrastructure, including Coordinated Regional Climate Downscaling Experiment (CORDEX). We downloaded 7 CORDEX simulations over Central Asia (CAS) and the Middle East and North Africa (MENA) domains, covering South Caucasus territory (Fig.1. a,b). Two our simulations with the same boundaries and with different configuration over the domain centered to South Caucasus region and with the $15 \mathrm{~km}$ resolution from two RCMs - RegCM4 and WRF have also been evaluated (Fig.1. c).

All RCMs are forced with ERA-Interim - reanalysis of the global atmosphere dataset. The ERA-Interim atmospheric model and reanalysis system uses cycle 31r2 of ECMWF's Integrated Forecast System (IFS), configured for the spatial resolution - T255 spherical-harmonic representation for the basic dynamical fields and a reduced Gaussian grid with approximately uniform $79 \mathrm{~km}$ spacing for surface and other grid-point fields.

For the reference data, we used global gridded observations (CRU) and TRMM precipitation monthly data.

\section{A. Reference data}

For validation of individual models, also for ensemble the gridded global data set of the Climate Research Unit (CRU) latest version TS 4.03, released on 15 May 2019, covering the period 1901-2018 Coverage: all land areas (excluding Antarctica) at $0.5^{\circ}$ resolution for 6 variables were used. This monthly observational data sets are based on statistical interpolation methods, which are gridded time-series and represent one of the most comprehensive observational data sets available [25].

TRMM has provided critical precipitation measurements in the tropical and subtropical regions of our planet, since its launch in 1997. The Precipitation Radar (PR) looked through 
INTERNATIONAL JOURNAL OF ENERGY and ENVIRONMENT

DOI: $10.46300 / 91012.2021 .15 .10$

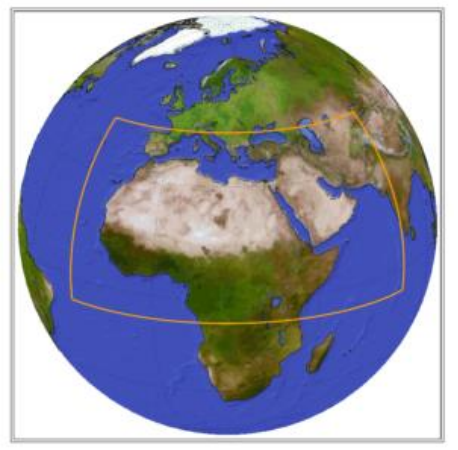

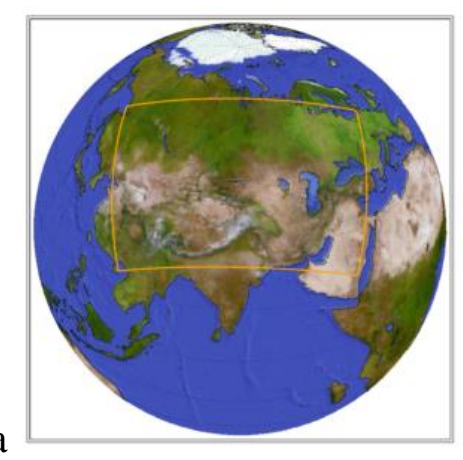

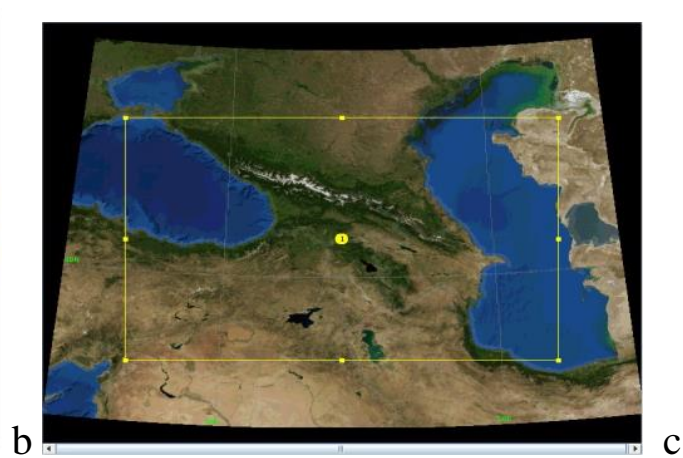

T. Davitashvili, N. Kutaladze, R. Kvatadze, L. Megrelidze, G. Mikuchadze, I. Samkharadze

Fig.1. a, b-CORDEX Middle East and North Africa (MENA) and Central Asia (CAS) domains; c- Caucasus domain (CAU).

the precipitation column, and provided new insights into tropical storm structure and intensification. The TRMM Microwave Imager (TMI) measured microwave energy emitted by the Earth and its atmosphere to quantify the water vapor, the cloud water, and the rainfall intensity in the atmosphere. The most relevant TRMM-related products for climate research are TMPA (Multi-satellite Precipitation Analysis) 3B43 monthly precipitation averages available in $0.25^{\circ}$ spatial resolution, covering $50^{\circ} \mathrm{N}$ to $50^{\circ} \mathrm{S}$ for 1998 present [26].

\section{B. Climate models used in the study}

All RCMs used in this study are hydrostatic atmospheric circulation models aimed to run over limited areas. The RCM names, responsible institutions for their simulations, resolutions, simulation periods and domains are presented in the table 1.

The ALARO-0 model is a configuration of the ALADIN model that is developed, maintained and used operationally by the 16 countries of the ALADIN consortium. The dynamical core of the ALADIN model 120 is based on a spectral spatial discretization and a semi-implicit semi-Lagrangian time stepping algorithm. The ALARO-0 configuration is based on the physics parameterization scheme 3MT (Modular Multiscale Microphysics and Transport), which handles convection, turbulence and microphysics.

REMO is a three-dimensional atmosphere model developed at the Max Planck Institute for Meteorology in Hamburg, Germany and currently maintained at the Climate Service Center Germany (GERICS) in Hamburg. The physical packages originate from the global circulation model ECHAM4, although many updates have been introduced. The vertical atmospheric levels are represented in a hybrid sigmapressure coordinate system. Horizontally, REMO has a spherical Arakawa C grid.

RCA4. Since 1997 the Rossby Centre has developed an international standing in the field of regional climate

modelling with the development of the atmospheric model RCA, at SMHI. RCA is based upon the numerical weather prediction (NWP) model HIRLAM. The RCA4 dynamical core is a two time-level, semi-Lagrangian, semi-implicit scheme with six-order horizontal diffusion applied to the prognostic variables.

HadRM3P is limited-area regional climate model widely used worldwide as part of the PRECIS (Providing Regional Climates for Impacts Studies) system, which was developed at the Hadley Centre of the United Kingdom Met Office. Model has $0.44 \times 0.44$ degrees' resolution with a rotated pole to achieve approx. $50 \mathrm{~km}$ x $50 \mathrm{~km}$ resolution on 19 levels over Central Asia domain (CAS-44 domain) representing the period from 1990 to 2011.

RegCM4. Regional Climate Model RegCM is developed at ICTP (International Center for Theoretical Physics). It uses the radiation scheme of the NCAR CCM3, the cloud scattering and absorption parameterization, whereby the optical properties of the cloud droplets are expressed in terms of the cloud liquid water content and an effective droplet radius. The soil hydrology calculations include predictive equations for the water content of the soil layers. Simulations with two different versions of the model RegCM v.4.3 and RegCM v4.7.0 over all three domains are evaluated in this paper. RegCM v.4.3 was run at the Boğaziçi University, Turkey, over CAS and MENA, with $0.440 \times 0.440$ resolution. The Georgian team of researchers performed simulation over Caucasus domain with $\mathrm{RegCM}$ v 4.7.0.

WRF-ARW v3.9.1.1. Weather Research and Forecasting model is a next-generation mesoscale numerical weather prediction system designed to serve both operational forecasting and atmospheric research needs (http://www.wrfmodel.org). It is a non-hydrostatic model, with several available dynamic cores as well as many different choices for physical parameterizations suitable for a broad spectrum of applications across scales ranging from meters to thousands of kilometers. The dynamic cores in WRF include a fully massand scalar-conserving flux form mass coordinate version. The physics package includes microphysics, cumulus parameterization, planetary boundary layer (PBL), land surface models (LSM), longwave and shortwave radiation. Georgian team performed simulation with WRF over Caucasus 
INTERNATIONAL JOURNAL OF ENERGY and ENVIRONMENT

DOI: $10.46300 / 91012.2021 .15 .10$
T. Davitashvili, N. Kutaladze, R. Kvatadze, L. Megrelidze, G. Mikuchadze, I. Samkharadze

domain.

Table I. Summary of data used in the study

\begin{tabular}{|c|c|c|c|}
\hline set/version & Time range & Resolution & Domain \\
\hline \multicolumn{4}{|c|}{ Observation \& reanalysis } \\
\hline CRUvTS 4.03 & $1901-2018$ & $0.5^{0} \times 0.5^{0}$ & Global \\
\hline TRMM & $\begin{array}{l}1 / 1998- \\
6 / 2013\end{array}$ & $0.25^{0} \times 0.25^{0}$ & $\begin{array}{c}\text { Tropics/Mid- } \\
\text { latitudes }\end{array}$ \\
\hline ERA-Interim & $\begin{array}{l}1979-\text { to } \\
\text { near present }\end{array}$ & $79 \mathrm{~km}$ & Global \\
\hline \multicolumn{4}{|c|}{ Climate models } \\
\hline ALARO-0 (RMIB-UGent) & $1980-2017$ & $0.22^{0} \times 0.22^{0}$ & CAS \\
\hline REMO (HZG-GERICS) & 1979-2017 & $0.22^{0} \times 0.22^{0}$ & CAS \\
\hline RegCM v 4-3 (BOUN) & $1979-2005$ & $0.44^{0} \times 0.44^{0}$ & CAS \\
\hline HadRM3P (MOHC) & $1990-2011$ & $0.44^{0} \times 0.44^{0}$ & CAS \\
\hline RCA4 (SMHI) & $1980-2010$ & $0.22^{0} \times 0.22^{0}$ & MENA \\
\hline RCA4 (SMHI) & $1980-2010$ & $0.44^{0} \times 0.44^{0}$ & MENA \\
\hline RegCM v 4 (BOUN) & $1980-2010$ & $0.44^{0} \times 0.44^{0}$ & MENA \\
\hline RegCM v 4.7.0 & $1985-2015$ & $0.15^{0} \times 0.15^{0}$ & $\mathrm{CAU}$ \\
\hline WRF-ARWv3.9.1.1 & $1985-2015$ & $0.15^{0} \times 0.15^{0}$ & $\mathrm{CAU}$ \\
\hline
\end{tabular}

latitudes. Atmospheric precipitation on the country territory

III. The Regional Climate Model Evaluation System (RCMES)

RCMES is an enabling tool of the NASA for evaluating climate models on regional and continental scales using observational datasets from a variety of sources. RCMES provides a framework for performing systematic evaluations of climate simulations, such as those from the CORDEX, using in situ observations, as well as satellite and reanalysis data products.

RCMES is composed of two main components, the Regional Climate Model Evaluation Database (RCMED) and the Regional Climate Model Evaluation Toolkit (RCMET). RCMED bringing together massive amounts of observational and model data, but also dealing with the wide variety of sources and formats of data, necessitating significant investments in computer and personnel resources to transfer, decode, (re)format, (re)archive, and analyze the data.

RCMET includes a software suite for calculating statistical metrics used in model evaluations and visualizations. RCMET includes a Python OSS library for common climate model evaluation tasks as well as a set of user-friendly interfaces for quickly configuring a model evaluation task. Model-evaluation metrics and visualization generally vary widely according to users and targets; RCMET includes the capability to incorporate user-defined metrics as well as pathways to extract partially processed data (e.g., both model and reference data regridded onto a common grid) so that users can do their own specific data processing and visualizations [27-29].

\section{COUNTRY Climatology}

Georgia, due to its geographical location, is under the influence of the circulation of temperate and subtropical almost all year is conditioned by cyclonic activities. However, precipitation associated with intra-mass processes are occurred quite often mainly in the warm period of the year in Eastern Georgia, and throughout the year in Western part of the country.

In the formation of climate of Georgia, mainly zonal circulation takes place. Sometimes it destroys the meridian circulation, during which there is an intrusion of colder air masses from the north, and warmers - from the south. In such cases, special significance obtains the Greater and Lesser Caucasus (South Georgian highlands) ranges. Highmountainous system of the Caucasus prevents a direct invasion of cold air masses from the north. Therefore, even arctic invasions in Georgia are mitigated as a result of their transformation over the Black and Caspian Sea. During the propagation of air masses from the West to Likhi ridge (submeridional range connecting the Greater and Lesser Caucasus, dividing the country climatically, watershed of the Black and Caspian Seas), they feel forced ascent and is accompanied by intense rainfall. Because of the foehn effect in Eastern Georgia such processes are often continued without precipitation. This type is the most frequent circulation process in Georgia, so it significantly affects distribution of precipitation on the country territory (Fig. 2.).

Synoptic processes through which air masses distributed on the territory of the Caucasus, and in particular, Georgia, grouped into the following types: western, eastern, two-sided, anticyclonic and wave disturbances developed in the southern regions of the Caucasus. Convective processes also participate in the formation of weather and are more pronounced in the warm period of year.

Due to the country climate regime, territory was divided in 
INTERNATIONAL JOURNAL OF ENERGY and ENVIRONMENT DOI: $10.46300 / 91012.2021 .15 .10$
T. Davitashvili, N. Kutaladze, R. Kvatadze, L. Megrelidze, G. Mikuchadze, I. Samkharadze eight sub-regions to examine the simulation performance across the experiments on different sub-regions. These regions mostly cover Georgia's territory but also include some neighboring parts, according to the factors of local climate formation. On Fig. 2. location and names of sub-regions are presented, where R01, R02 and R03 are respectively western, central and eastern parts of Greater Caucasus mountains, R04 Kolkheti lowlands, R05 - central part including Likhi range, R06 - Adjara Black Sea coastal zone with adjacent mountains, R07 - Lesser Caucasus mountains, R08 - eastern country plane territory.
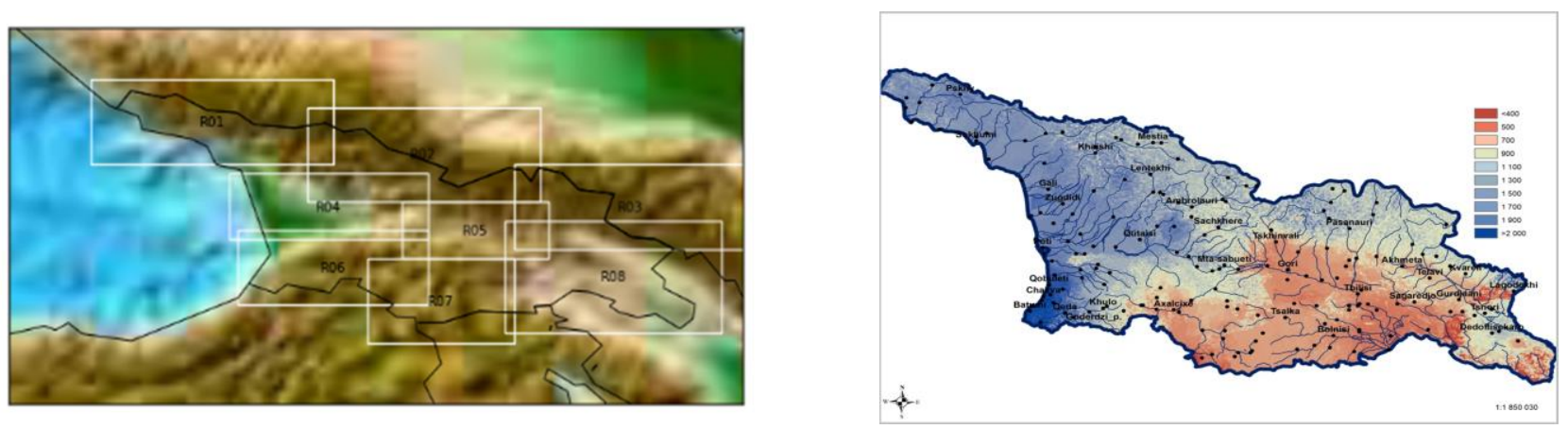

Fig.2. Study (Caucasus) domain: the color contours represent the terrain elevation, the numbered boxes with white boundaries indicate the eight sub-regions in which the area-mean time series are evaluated (left); annual precipitation climatology (right).

\section{RESULTS}

The analysis focuses on how the model simulates surface climate (precipitation) in response to the large-scale forcing imposed by the ERA-Interim reanalysis and by local topographical features. Study presented here is performed over the interior domain to eliminate the buffer zone where the direct effect of the lateral boundary conditions is maximum.

\section{A. Evaluation metrics}

Different metrics have been used in order to represent the performance of climate models in simulating climatic conditions. Besides computing the mean bias and root mean square error (RMSE), the degree of statistical similarity between two climatic fields was quantified in the form of normalized Taylor diagrams. This can be considered as combination of different measures such as the centered (or bias removed) RMSE, spatial standard deviation (STD) and spatial correlation. The Taylor diagrams reported in the present study are based on 16-year annual and seasonal means in grid points. The spatial distribution of mean precipitation and the annual cycle of mean monthly precipitation are also presented.

\section{B. Uncertainties assessment}

The accuracy of reference data is among the most important concerns in model evaluation. All observations and/or analyses include errors of unknown/estimated magnitudes; e.g., analyses based on surface station data are directly affected by local station density. This especially true for the Caucasus region in which station density varies substantially according to regions. Uncertainties in model evaluation originating from reference data are examined using two different reference datasets. In addition to CRU, the Tropical Rainfall Measuring Mission (TRMM) was selected for 1998-2005, overlapping with the period when models evaluation was performed.

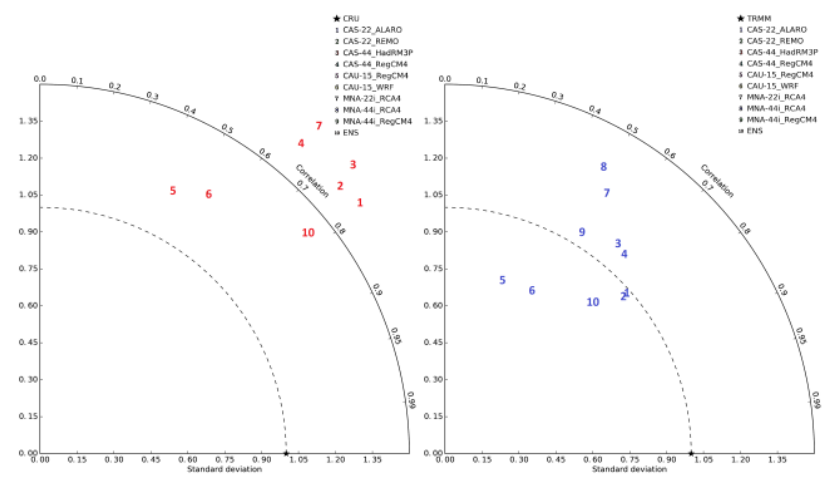

Fig. 3. Evaluation of the simulated precipitation climatology over the land using two different reference datasets: CRU (left) and TRMM (right), indicate the model ensemble evaluated against different reference data.

All RCMs yield higher spatial correlations with the CRU than TRMM. The standardized deviations and RMSE are smaller in absolute values against CRU, but the same normalized metrics are closer to remote-sensing data, forasmuch as the spatial variability of the TRMM is larger than in situ gridded data (CRU). So normalization by bigger quantities produces reduced differences between modeled and reference data (in this case TRMM) (Fig. 3).

Fig. 4 shows the spatial distribution of mean annual precipitation biases averaged over the entire period compared to the CRU and TRMM datasets. In all seasons (not shown) precipitation bias against CRU data mostly ranges between $\pm 2.4 \mathrm{~mm}$ /day over the most of domain, except in summer, when the deviation increasing up to $\pm 3.2 \mathrm{~mm} /$ day. Differences between models and TRMM data range between $\pm 2.0 \mathrm{~mm}$ /day in the cold period of year (NDJFM - November to March) and 
INTERNATIONAL JOURNAL OF ENERGY and ENVIRONMENT DOI: $10.46300 / 91012.2021 .15 .10$

for annual biases. During the warm period (AMJJASO - April to October) differences are higher $( \pm 2.4 \mathrm{~mm} /$ day $)$.

Finally, including longer comparison period the better fit was obtained with CRU, although there are some systematically occurred features in the spatial distribution of these differences. Relative to CRU it is noticeable wet bias over Caucasus throughout the year, more apparent in the west part in winter season, shifting to the east in summer months. Dry bias is the most evident in summer over the plain territory, with greatest underestimation on the Black Sea costal area and adjacent lowlands. As for TRMM, deviations spatial features is almost the same, but in contrary with CRU, for all simulations dry bias, occurred again over lowlands and plain territory and especially clearly expressed over west country coastal zone and lowland territory. It is dominant through entire year, precipitation overestimation depicted over the Greater Caucasus most explicitly seen in summer. Therefore, evaluation of models against two observation datasets demonstrates the spatial features of precipitation biases and bias pattern is comparable with the terrain profile.

The differences between precipitation evaluations based on the two observation datasets, may have resulted from the difference in the observational platform and methodologies. This examination shows that, quality control and crossexamination of reference datasets are important for model evaluations.

\section{Evaluation results}

In this study a multi-year evaluation of overland precipitation against the CRU dataset is carried out from 1990 to 2005. As already mentioned, the most noticeable feature is the general moisture shift over the Greater and Lesser Caucasus (western part) mountains and dry bias in the Black Sea coastal area and adjacent Kolkheti lowlands (Fig. 4). The spatial patterns of wet biases for all simulations are similar, with the largest magnitudes being located over Geater Caucasus range. However, overestimation in the HaDRM3P and RegCM4 coarser resolution simulations are generally larger and extended over west Georgia lowlands. The dry bias over lowlands and plains of the territory is found in all simulations except RegCM4 with $0.44^{0}$ resolution integrated on MENA (Middle East and North Africa) domain. It seems that coarser resolution simulations $\left(0.44^{0}\right)$ generates greatest wet biases and MNA-RegCM4 is an outlier among six RCMs in the sense that it overestimates precipitation over almost the entire study territory, whereas finer resolution runs $\left(0.22^{0}\right.$, $0.15^{\circ}$ ) are main producers of mentioned underestimation over lowland areas.

All RCMs calculations except for the local simulations performed for the Caucasus region, seem to overestimate the precipitation over the high mountain regions and underestimate the low heights, resulting in the least deviated ENS results relative to observations in the $\pm 1 \mathrm{~mm}$ /day range.

Overall, all models simulate the spatial variations in the annual mean precipitation over Georgia (R02, R03, R05, R07,
T. Davitashvili, N. Kutaladze, R. Kvatadze, L. Megrelidze, G. Mikuchadze, I. Samkharadze
R08) with the spatial pattern correlation coefficients between 0.5 and 0.8 and standardized deviations (the spatial standard deviation of the simulated atmospheric precipitation normalized by that of the observed data) of 1.1-1.65 with respect to CRU data, except RCA4 and RegCM4, integrated for MENA domain on $0.44^{0}$ grid, with much higher STD up to 1.6-2.4 (Fig. 3). Fig. 3 also shows that the multi-model ensemble mean (ENS) along with ALARO yields the smallest RMSE. Investigation those metrics by regions also reveals considerable differences, i.e. correlation is much lower (0.20.5 ) in west part of the country (R01, R04, R06), especially in the Black Sea adjacent lowlands (R01), where greatest RMSE (up to 4) and STD (up to 2.7) is obtained.

Comparison of the simulated annual cycle against the CRU analysis for the sub-regions shows that the multi-model ensemble agrees relatively well with the observed climatology in these regions, with the exception of region R01. However, it should be noted that there are significant differences between selected nine simulations having not identical annual cycles and variability range in monthly mean precipitation averaged over sub-regions, with differences up to 6-7 $\mathrm{mm} /$ day for separate models. Accordingly, model biases vary noticeably according to regions and seasons (Fig. 5).

Fig. 5 shows time dependence of model deviations since precipitation offsets are not constant over time. They have a more or less clear annual cycle: there is one RCMs (MNARegCM4) with a constant negative precipitation bias through the entire year, for other five models precipitation is mostly underestimated in summer (up to 3-4 $\mathrm{mm} / \mathrm{day}$ ), whilst overestimated to a varying extent in the rest of the year resulting ensemble simulations overall slightly positive bias. Therefore, the seasonal variation in the magnitude of the bias in area-average precipitation means that the ENS simulation has more extreme annual cycle than the annual cycle of the observations. In the cold period (NDJFM), all regions of the study territory have a wet bias. This appears to be largest over the western and central part of Caucasus mountains. Dry bias in area-mean precipitation is greatest during autumn and especially in summer. In these seasons, dry biases extend over entire low elevation regions including the Greater Caucasus western part. This can be related to simulation of cold-season snowpack in high-elevation regions and/or the lack of resolutions both in model simulations and the CRU data, suitable for representing the large orographic variations and associated variations in atmospheric precipitation in the mountainous region. As well as in modifying synoptic systems entering the domain enhancing the role of the large scale frontal processes while diminishing the locally induced intramass precipitation that is mostly related to extreme rainfall events. 
INTERNATIONAL JOURNAL OF ENERGY and ENVIRONMENT

DOI: $10.46300 / 91012.2021 .15 .10$
T. Davitashvili, N. Kutaladze, R. Kvatadze, L. Megrelidze, G. Mikuchadze, I. Samkharadze
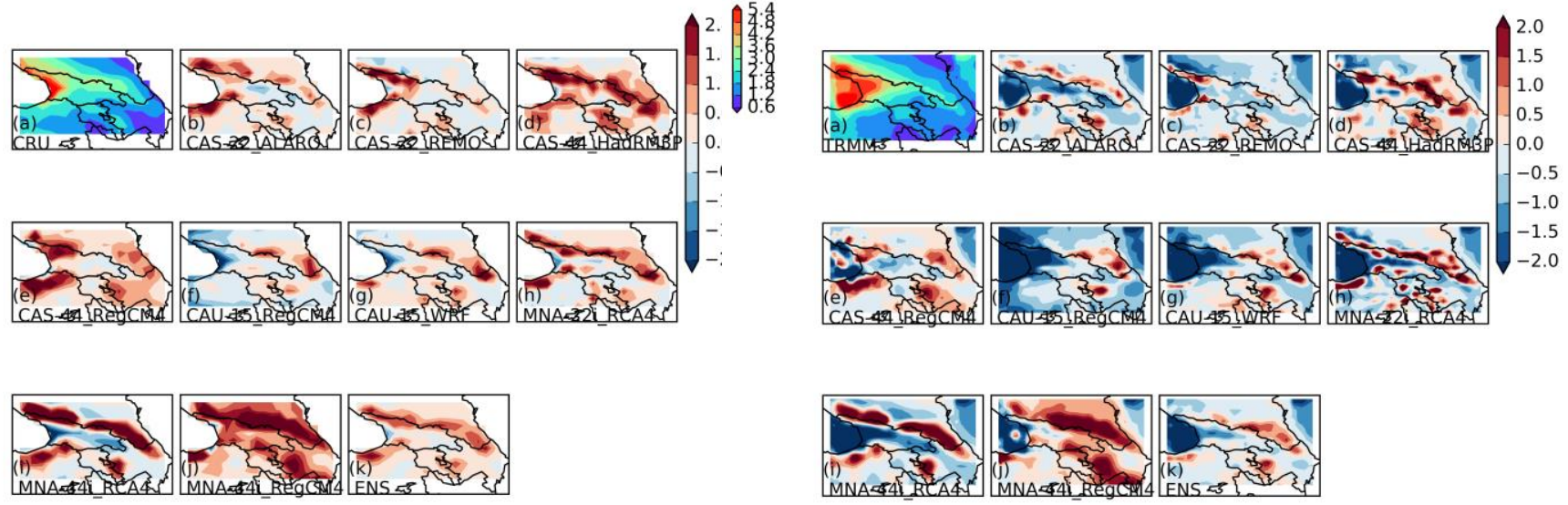

Fig. 4. Annual-mean surface precipitation (mm) from the CRU (a) (left), and TRMM (a) analysis (right). The biases (mm) from the reference data for $(\mathrm{b})-(\mathrm{j})$ the individual models and $(\mathrm{k})$ the multi-model ensemble (ENS).

Fig. 6 presents the normalized biases and interannual variability in terms of the percentage of the temporal standard deviations of the CRU data over the 16-year period of the simulated atmospheric precipitation in the eight sub-regions during each season. The scaled model bias shows that the wet bias over the Caucasus mountains is common for nearly all models (except RCMs integrated over Caucasus) and is more distinct in the cold period of year (NDJFM) over western mountainous part, whereas getting sharper in east and south Caucasus in the warm period (AMJJASO). The dry biases
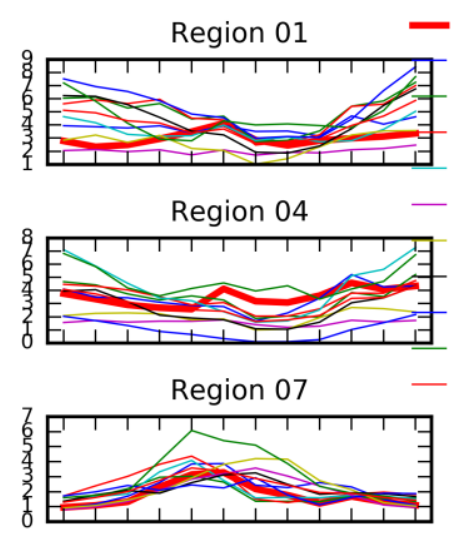

generated by CAU-15 are less strong during almost entire year (by $50 \%-150 \%$ of the observed interannual variability) and ENS underestimation over the mountainous region R01 in summer, is the only exception. As for dry bias on the intermountain area (R04, R05, R08) negative deviations are systematic for most of models (except MNA-RegCM4 and CAS-HaDRM3P) in the warm period (AMJJASO), getting especially evident for west Georgia lowlands (R04) in summer months.

Fig. 5. Simulated and observed (CRU, thick red) precipitation annual cycle $(\mathrm{mm})$ for eight sub-regions. The thin red line indicates the multi-model ensemble precipitation.

Models skill in simulating the interannual variability of the seasonal precipitation is further examined using RMSE and the temporal correlation coefficients between the simulated and CRU data. The resulting RMSE (Fig. 6) exceeds the interannual variability of the CRU data regardless the models and seasons (i.e., normalized RMSE $>100 \%$ ), especially during winter, when the normalized RMSE for the multi-model ensemble is not less than $240 \%$ while for separate RCMs is well above $400 \%$ mostly for regions belonging to Greater Caucasus range (R01, R02, R03). As for ENS, it yields the smallest RMSE in spring (MAM). Like the bias, it reveals systematic behavior in terms of regional distribution, i.e. throughout the year RMSE is the greatest over the Greater Caucasus range, enhancing in the west part in the cold period and in the east in the warm period of the year. Additionally, for annual and cold period means because of mostly underestimation is evident, ENS RMSE is greater than for separate models that are ALARO and RCMs integrated over Caucasus domain, having generally negative bias.

The spread of bias fields mostly ranges between $-240 \%$ and $+240 \%$, however MNA-RegCM4 and CAS-HaDRM3P (overestimation) models are exceeding these limits in winter- 
INTERNATIONAL JOURNAL OF ENERGY and ENVIRONMENT DOI: $10.46300 / 91012.2021 .15 .10$
T. Davitashvili, N. Kutaladze, R. Kvatadze, L. Megrelidze, G. Mikuchadze, I. Samkharadze spring period almost all over the country. Other models are beyond these ranges over Greater Caucasus regions. Underestimation greater than these limits is common not for any specific model but for the lowland and plain territory (R01, R08) in summer-autumn seasons. CAS-HaDRM3P in the cold period of year and MNA-RegCM4 in warm period typically show a strong wet bias when compared to the CRU observational dataset. In general, RegCM4 and WRF, integrated over CAS and Caucasus domains, performs among the best climate models: i.e., producing close to zero mean annual bias due to the least biased performance during the period from November to March. Hence, higher resolution simulations (RegCM4, WRF) are expected to decrease the mean bias fields, and actually the standard deviation of bias averaged over the region in each season is smaller in case of RegCM4 and WRF compared to the ensemble (Fig. 6). The wide range of the spread in seasonal biases can be directly attributed to the different topography and parameterizations implemented in the evaluated climate models.

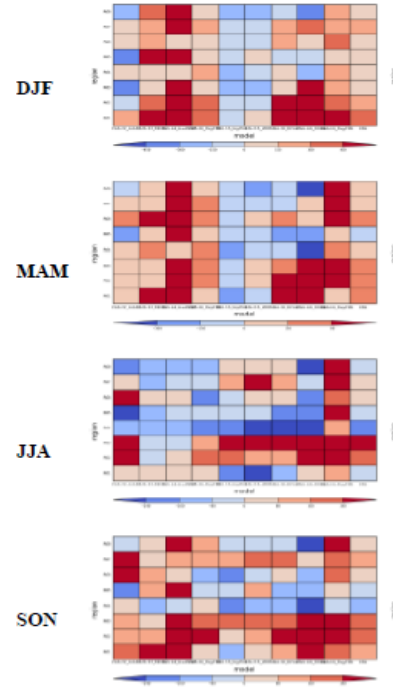

(a) Bias
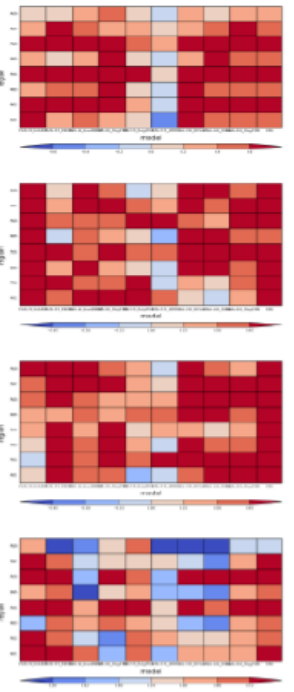

(b) Correlation
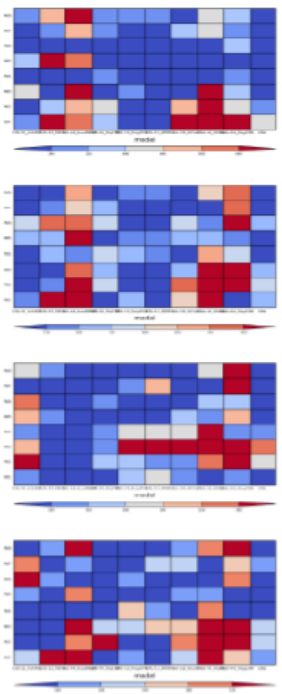

(c) RMSE
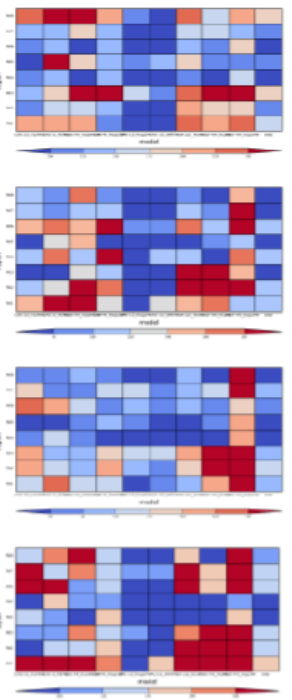

(d) STD

Fig.6. Regional (a) bias, (b) temporal correlation coefficients, (c) root mean square error and (d) temporal standard deviation of simulated average seasonal precipitation relative to CRU observations. Seasons are defined as follows: winter-DJF

(December-February), spring-MAM (March-May), summer-JJA (June-August) and autumn-SON (September-November). The bias, standard deviation, and RMSE are normalized by the standard deviation of the CRU data.

The model biases also vary systematically according to regions. For spring, the most noticeable systematic biases are the wet bias over the almost entire territory with relatively smaller dryness revealed in the central mountainous part (R05 Likhi range). For autumn, the most systematic biases are again the wet bias in the mountainous regions including east Georgia plains (R08), whilst dry bias is enlarged relative to spring and cover also west Georgia lowlands. In winter, wet bias is evident relative to other seasons as shown in Fig. 6. As for summer, dry bias getting the dominant compared to other seasons and it varies closely with orography. This feature of orography dependence bias is noticeable during whole year but most evident in summer. The evaluation of the temporal standard deviation, a surrogate for the interannual variability, shows that all models perform reasonably well in simulating the interannual variability of spring precipitation for all subregions. Most of RCMs overestimate the interannual variability of the cold season precipitation; overestimation is greatest for the models integrated over the MENA domain. For all seasons finest resolution simulations, integrated over Caucasus domain have the least STD.
Correlation coefficients between the simulated and CRU time series (Fig. 6) also shows that climate models examined in this study generally perform better in simulating the phase of the interannual variation in the over land precipitation during autumn (SON) than in other seasons. As for separate simulations, the poorest correlation was found for WRF model integrated on Caucasus domain. Overview of seasonal means approved that degree of matching with observation vary by regions and depends on season. In contrary with annual correlations, west Georgia regions (R01, R04, R06) were found as almost not correlated with observations, whilst the same regions 04 and 06 have the highest scores for winter and autumn seasonal means.

\section{CONCLUSION}

In the present study, six climate models have been evaluated over 16-year reference period (1990-2005) against CRU observational dataset, while the TRMM data have been used for comparison. The aim of this study is to provide useful information on general capabilities of given models in reproducing climatic conditions over the South Caucasus 
region. This article does not attempt to identify the physics and dynamics of the model responsible for the differences in RCM performance. In general, the annual precipitation cycle averaged over the study region is relatively well represented by ensemble modeling. According to the spatial distribution of seasonal precipitation, models performing well for annual precipitation do not necessarily perform well in separate seasons. The model performance varies widely and, often systematically, according to regions and seasons. These characteristics in model errors make it difficult to design a set of model weightings that can be universally applied to the construction of multi-model ensemble.

According to the findings reported in the present work, the following considerations can be made: (i) there is not a single model outperforming the other ones in all aspects, but it is also important to note that all models have their strength and weaknesses; (ii) higher resolution simulations may more adequately resolve over-land precipitation variations in the region; (iii) but due to the amplification of biases or the increased internal variability on small scales induced by strong local surface heterogeneities within the regional domain, higher resolution simulations not necessarily reduce the uncertainties; (iv) domain of model integration might has a significant impact; (v) model performances are also influenced by observational uncertainties and (vi) it is fundamental to test whether a RCMs is able to reproduce the mean climatology and temporal variability over a region using finer scale observations from different sources.

\section{ACKNOWLEDGMENT}

The research was funded by the Shota Rustaveli National Scientific Foundation of Georgia Grant \#FR17_548.

\section{References}

[1] IPCC, Climate change. 1995-the science of climate change. IPCC, WMO, p. 572, 1995.

[2] IPCC, Climate change 2001: the scientific basis. IPCC, WMO, p. 881, 2001.

[3] IPCC, Climate change 2007-synthesis report. Intergovernmental Panel on Climate Change, WMO, p. 73, 2007.

[4] G. Meehl, C. Covey, T. Delworth, R. Stouffer, M. Latif, B. Mcavaney, J.Mitchell, The WCRP CMIP3 multi-model dataset: a new era in climate change research. Bull. Am.Meteorol. Soc.(2007) 88:1383-1394.

[5] T. Reichler, J. Kim. Uncertainties in the climate mean state of global observations, reanalyses and the GFDL climate model. J.Geophys. Res.(2008) 113:D05106. doi:10.1029/2007JD009278.

[6] P. Gleckler, K. Taylor, C. Doutriaux, Performance metrics for climate models. J.Geophys. Res. (2008) 113. doi:10.1029/2007JD008972.

[7] T. Reichler, J. Kim, Haw well do coupled models simulate today's climate? Bull. Am.Meteorol. Soc.(2008) 89:303311 .

8] G.Nikulin, C. Jones, P. Samuelsson, F. Giorgi, M. Sylla, G. Asrar, M. Buchner, R.Cerezo-Mota, Precipitation climatology in an ensemble of CORDEX-Africa regional climate simulations. J.Clim.(2012) doi:10.1174/JCLI-D11-00375.

[9] Russo E., Kirchner I., Pfahl S., Schaap M., and Cubasch U.: Sensitivity studies with the regional climate model COSMO-CLM 5.0 over the CORDEX Central Asia Domain, Geosci. Model Dev., 12, 5229-5249, https://doi.org/10.5194/gmd-12-5229-2019, 2019.

[10] Tugba Ozturk, M. Tufan Turp, Murat Türkeş, M. Levent Kurnaz. Projected changes in temperature and precipitation climatology of Central Asia CORDEX Region 8 by using RegCM4.3.5, Atmospheric Research, Volume 183, 1 January 2017, Pages 296-307 https://doi.org/10.1016/j.atmosres.2016.09.008.

[11]Deitch M.J., Sapundjieff M.J., Feirer S.T., (2017) Characterizing precipitation variability and trends in the world's Mediterranean-climate areas. Water 9:259. https://doi.org/10.3390/w9040259.

[12] Zittis G., Hadjinicolaou P., Klangidou, M. et al. A multimodel, multi-scenario, and multi-domain analysis of regional climate projections for the Mediterranean. Reg Environ Change 19, 2621-2635 (2019). https://doi.org/10.1007/s10113-019-01565-w,

[13]Zittis G., (2018). Observed rainfall trends and precipitation uncertainty in the vicinity of the Mediterranean, Middle East and North Africa. Theor Appl Climatol 134:1207. https://doi.org/10.1007/s00704-0172333-0.

[14]Lionello P, Scarascia L., (2018) The relation between climate change in the Mediterranean region and global warming. Reg Environ Chang 18(5):1481-1493. https://doi.org/10.1007/s10113-018-1290-1.

[15] Almazroui M., Islam M. N., Al-Khalaf A. K., Saeed, F., (2016). Best convective parameterization scheme within RegCM4 to downscale CMIP5 multi-model data for the CORDEX-MENA/Arab domain. Theoretical and Applied Climatology, 124(3-4), 807-823. DOI 10.1007/s00704015-1463-5.

[16] Almazroui M., Islam M.N., Alkhalaf A.K. et al. (2016) Simulation of temperature and precipitation climatology for the CORDEX-MENA/Arab domain using RegCM4. Arab J Geosci, 9(1), 13, DOI 10.1007/s12517-015-20457.

[17] Almazroui M., (2019). Temperature Changes over the CORDEX-MENA Domain in the 21st Century Using CMIP5 Data Downscaled with RegCM4: A Focus on the Arabian Peninsula. Advances in Meteorology, 2019. DOI 10.1155/2019/5395676.

[18] Bucchignani E., Mercogliano P., Rianna G., Panitz H. J., (2016). Analysis of ERA-Interim-driven COSMO-CLM simulations over Middle East - North Africa domain at different spatial resolutions. International Journal of Climatology, 36(9), 3346-3369. DOI 10.1002/joc.4559.

[19] Bucchignani E., Cattaneo L., Panitz H. J., Mercogliano, P. (2016). Sensitivity analysis with the regional climate model COSMO-CLM over the CORDEX-MENA domain. 
INTERNATIONAL JOURNAL OF ENERGY and ENVIRONMENT DOI: $10.46300 / 91012.2021 .15 .10$

Meteorology and Atmospheric Physics, 128(1), 73-95. DOI 10.1007/s00703-015-0403-3.

[20] Bucchignani E., Mercogliano P., Panitz H. J., Montesarchio M,. (2018). Climate change projections for the Middle East-North Africa domain with COSMOCLM at different spatial resolutions. Advances in Climate Change Research, 9(1), 66-80.

DOI 10.1016/j.accre.2018.01.004

[21] Ozturk T., Turp M. T., Türkeş M., Kurnaz M. L., (2018). Future projections of temperature and precipitation climatology for CORDEX-MENA domain using RegCM4.4. Atmospheric Research, 206, 87-107. DOI 10.1016/j.atmosres.2018.02.009.

[22] Spinoni J., Barbosa P., Bucchignani E., Cassano J., Cavazos T., Christensen J. H., Christensen O. B., Coppola E., Evans J., Geyer B., Giorgi F., Hadjinicolaou P., Jacob D., Katzfey J., Koenigk T., Laprise R., Lennard C. J., Kurnaz M. L., ... Nikulin G., Ozturk T., Panitz H.-J., ... Zittis G., Dosio A., (2020). Future Global Meteorological Drought Hot Spots: A Study Based on CORDEX Data. Journal of Climate, 33(9), 3635-3661. DOI 10.1175/jclid-19-0084.1.

[23]Zittis G., Hadjinicolaou P., (2017). The effect of radiation parameterization schemes on surface temperature in regional climate simulations over the MENA-CORDEX domain. International Journal of Climatology, 37(10). DOI 10.1002/joc.4959.

[24]Zittis G., Hadjinicolaou P., Klangidou M., Proestos Y., Lelieveld J., (2019). A multi-model, multi-scenario, and multi-domain analysis of regional climate projections for the Mediterranean. Regional Environmental Change, 19(8), 2621-2635. DOI 10.1007/s10113-019-01565-w.

[25]I. Harris et al. Updated high-resolution grids of monthly climatic observations - the CRU TS3.10 Dataset (2014). doi:10.1002/joc.3711.

[26] Kim J., Guan B., Waliser D.E. et al. Winter precipitation characteristics in western US related to atmospheric river landfalls: observations and model evaluations. Clim Dyn 50, 231-248 (2018). https://doi.org/10.1007/s00382-0173601-5.

[27] Peter B. Gibson, Duane E. Waliser, Huikyo Lee, Baijun Tian, Elias Massoud, Climate Model Evaluation in the Presence of Observational Uncertainty: Precipitation Indices over the Contiguous United States, J. $\begin{array}{lllll}\text { Hydrometeor. } & \text { (2019) } 20 & \text { (7): 1339-1357. }\end{array}$ https://doi.org/10.1175/JHM-D-18-0230.1.

[28] Lucas-Picher, R. Laprise, K. Winger, 2017: Evidence of added value in North American regional climate model hindcast simulations using ever-increasing horizontal resolutions. Climate Dyn., 48, 2611-2633, https://doi.org/10.1007/s00382-016-3227-z.

[29] Lee H., Goodman A., McGibbney L., Waliser D. E., Kim J., Loikith P. C., Gibson P. B., Massoud E. C.: Regional Climate Model Evaluation System powered by Apache Open Climate Workbench v1.3.0: an enabling tool for facilitating regional climate studies, Geosci. Model Dev., 11, 4435-4449, https://doi.org/10.5194/gmd-11-44352018, 2018.
T. Davitashvili, N. Kutaladze, R. Kvatadze, L. Megrelidze, G. Mikuchadze, I. Samkharadze

\section{Creative Commons Attribution License 4.0 (Attribution 4.0 International, CC BY 4.0)}

This article is published under the terms of the Creative Commons Attribution License 4.0 https://creativecommons.org/licenses/by/4.0/deed.en_US 